Part of Journal of Research of the National Bureau of Standards, Volume 36, June 1946

\title{
HYGROSCOPICITY AND ELECTRODE FUNCTION (pH RESPONSE) OF GLASSES AS A MEASURE OF SERVICE- ABILITY
}

\author{
By Donald Hubbard
}

\section{ABSTRACT}

The $\mathrm{pH}$ responses of electrodes prepared from glasses of widely different composition have been compared with the hygroscopicity of the glasses. The resulting data indicate that glasses of low hygroscopicity, such as the chemical glasswares and common types of optical glasses, give $\mathrm{pH}$ responses that fall appreciably below the theoretical predicted from the Nernst equation and are incapable of producing satisfactory electrodes. Further, electrodes blown from glasses of intermediate hygroscopicity, such as the common bottle and sheet glasses, give $\mathrm{pH}$ responses more nearly approximating the theoretical, whereas the Corning 015 glass, whose superior $\mathrm{pH}$ response places it in a class by itself, has a very high hygroscopicity. These results strongly support the belief that adequate hygroscopicity is one of the primary factors in determining the suitability of a glass for $\mathrm{pH}$ measurements. The data also suggest that the $\mathrm{pH}$ response might well be used as a rapid test for the serviceability of optical glasses, i. e., the ability to maintain a clear polished surface upon exposure to the atmosphere. For this purpose it is necessary to determine the $\mathrm{pH}$ response over a range in which the "chemical durability" of the glass remains constant in order to avoid the voltage anomalies that accompany durability changes.

\section{CONTENTS}

I. Introduction_._.

II. Types of glasses.

III. Experimental procedure _. _

IV. Results and discussion $\ldots \ldots$

1. $\mathrm{pH}$ response in the acid range $\ldots \ldots \ldots \ldots \ldots$

2. $\mathrm{pH}$ response of glasses in regions of changing chemical durability. 517

V. Conclusions.

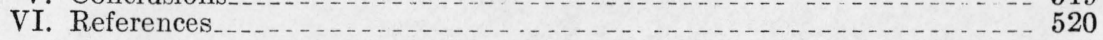

\section{INTRODUCTION}

The ability of a glass to function satisfactorily as an indicator of hydrogen-ion concentration, approximately in accord with the straight-line relation of the simplified Nernst equation, ${ }^{1}$ is known to

${ }_{1}^{1} E=0.000198 T \log 1 /\left[\mathrm{H}^{+}\right]=0.000198 T p H$, where $E$ is emf, $T$ is temperature degrees Kelvin, $p H=\log$ $1 /\left[\mathrm{H}^{+}\right]$, and $\left[\mathrm{H}^{+}\right]$denotes hydrogen-ion concentration or activity. 


\section{Journal of Research of the National Bureau of Standards}

be intimately associated with the water content of the glass $[1$, p. 78].2 As the serviceability of an optical glass, i. e., its ability to maintain a clear polished surface upon exposure to the atmosphere, has been shown to be largely dependent upon the hygroscopicity of the glass [2], it seems reasonable to believe that the serviceability might also be ascertained easily and quickly, at least qualitatively, by a determination of its hydrogen-electrode function.

In the present investigation the hygroscopicity and $\mathrm{pH}$ response were observed on a series of glasses of varying serviceability and a comparison was made of the data obtained on these properties.

\section{TYPES OF GLASSES}

A selection was made of 12 glasses that exhibited a wide range in serviceability. Vycor and Pyrex were chosen as glasses of superior serviceability, whereas the Dish and Corning 015 were selected because they had not maintained clear surfaces upon exposure to the atmosphere. The compositions of 11 of these glasses are given in table 1 .

Figures in bracketsindicate the literature references at? the end of this paper. 
TABLE 1.-Percentage compositions of glasses tested for hygroscopicity and $\mathrm{pH}$ response

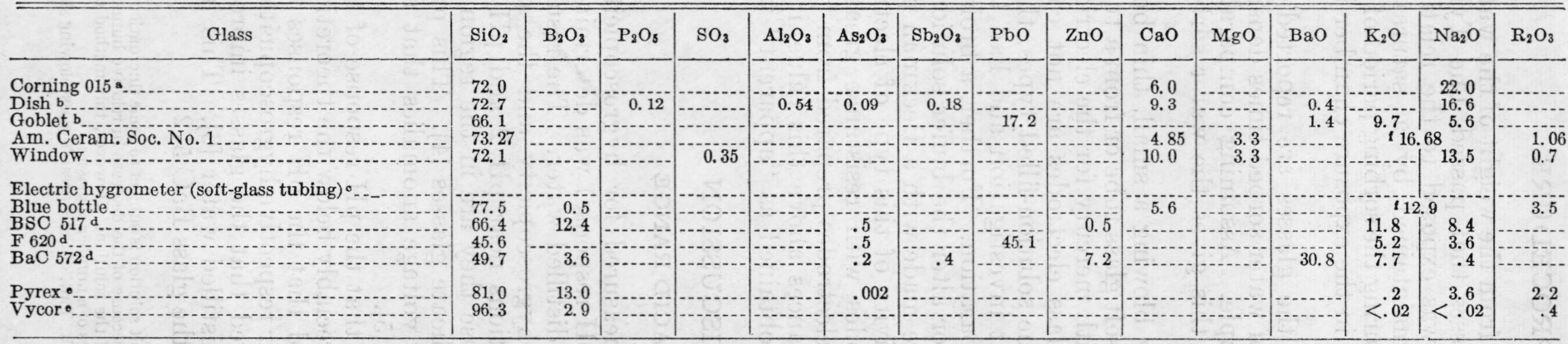

a D. G. MacInnes and M. Dole, The behavior of glass electrodes of different compositions, J. Am. Chem. Soc. 52, 29-36 (1930).

- Francis W. Dunmore, An electric hygrometer and its application to radio meteorography, J. Research NBS 20, 723 (1938) RP1102.

d Optical glasses.

$1 \mathrm{~K}_{2} \mathrm{O}$ and $\mathrm{Na}_{2} \mathrm{O}$ combined. 


\section{Journal of Research of the National Bureau of Standards}

\section{EXPERIMENTAL PROCEDURE}

The hygroscopicity data were obtained from the weight of the water sorbed by powdered samples of the glasses that passed The Tyler Standard Sieve No. 150. This powder was exposed to the relative humidity, approximately 95 percent, maintained by a saturated solution of $\mathrm{Na}_{2} \mathrm{HPO}_{4} \cdot 12 \mathrm{H}_{2} \mathrm{O}^{3}$ at $25^{\circ} \mathrm{C}$. During the sorbing period of 16 hours the air was circulated continuously in the exposure chamber by means of a small fan.

The hygroscopicity values for all of the glasses are reported in terms of known factors, namely, weight of water sorbed times density of the glass divided by weight of sample. Assuming comparable sieving and preparation of the samples, this gives the water sorbed for equal surfaces.

The glass electrodes were prepared by blowing a small, thin bulb of the experimental glass on the end of a soft glass tube or from a tube of the glass itself ${ }^{4}$ and filling the bulb with mercury for the electrical connection [3]. Although metal-filled glass electrodes are not considered as suitable for precise work as the solution-filled types, they were entirely satisfactory for the present investigation and had the advantage of simplicity and speed of preparation. Further, a broken electrode did not seriously contaminate or alter the buffer solutions.

All voltage and $\mathrm{pH}$ measurements were made with a Beckman $\mathrm{pH}$ meter, laboratory model G. The sensitivity of this type of electrometer decreases appreciably for electrodes with resistance greater than 500 megohms, and as many of the electrodes prepared from the glasses of low hygroscopicity had resistances above this value, it is desirable to consider the $\mathrm{pH}$ responses obtained as "apparent" $\mathrm{pH}$ responses.

\section{RESULTS AND DISCUSSION}

\section{PH RESPONSE IN THE ACID RANGE}

The silicate glasses, table 1, were measured for hygroscopicity, and their hydrogen-electrode function ( $\mathrm{pH}$ response) was determined after soaking the electrodes 24 hours in distilled water. The results in table 2 show the relation between hygroscopicity and the $\mathrm{pH}$ response obtained with two buffer solutions near $\mathrm{pH} 2$ and $\mathrm{pH} 4$. These two $\mathrm{pH}$ values were chosen because they are in the region of uniform chemical durability for most silicate glasses [4]. This procedure was desirable in order to avoid voltage anomalies that accompany durability changes of the glass [5].

From the data in table 2 it is evident that the $\mathrm{pH}$ response of the glasses with low hygroscopicity falls appreciably below the theoretical predicted from the Nernst equation, and that the $\mathrm{pH}$ responses for these glasses are in the same order as their respective hygroscopicities. During these experiments it was observed that the glasses improve in their $\mathrm{pH}$ response when soaked in distilled water [6]. This improvement was especially noticeable for the glass $\mathrm{BaC} 572$.

\footnotetext{
3 The relative humidity obtained by means of a saturated salt solution is subject to some fluctuation because of the difficulty of obtaining equilibrium rapidly and because of the decrease in relative humidity that occurs when a crust of the salt forms over the surface of the solution. However, this method does furnish an easy means of comparing the relative hygroscopicities of a number of glasses.

'Tubes of the experimental glasses were drawn by Thomas R. Tait, of the Bureau's glass-blowing shop.
} 
TABLE 2.-Comparison of hygroscopicity and $\mathrm{pH}$ response at $25^{\circ} \mathrm{C}$ of some typical commercial and optical glasses, after soaking the electrodes in distilled water for 24 hours

\begin{tabular}{|c|c|c|}
\hline Glass & Water sorbed & $\mathrm{pH}$ response \\
\hline $\begin{array}{l}\text { Corning } 015 \\
\text { Dish } \\
\text { Am. Ceram. Soc. No. } 1 \\
\text { Window } \\
\text { Electric hygrometer }\end{array}$ & $\begin{array}{l}m g \text { per } \mathrm{cm}^{3} \\
358 \\
88 \\
40 \\
39 \\
39\end{array}$ & $\begin{array}{l}\text { mo per } \mathrm{pH} \\
59 \\
58 \\
57 \\
56 \\
56\end{array}$ \\
\hline $\begin{array}{l}\text { Blue bottle } \\
\text { BSC } 517 \\
\text { F } 620 \\
\text { BaC } 572^{2} \\
\text { Pyrex }\end{array}$ & $\begin{array}{l}30 \\
5.5 \\
4.8 \\
2.2 \\
1.8\end{array}$ & $\begin{array}{l}54 \\
43 \\
39 \\
33 \\
18\end{array}$ \\
\hline
\end{tabular}

In order to observe the effect of time on $\mathrm{pH}$ response another set of electrodes was prepared from six of the typical glasses used in the previous series plus two others, and emf measurements were taken at intervals for 27 days. The data are given in table 3 . The $\mathrm{pH}$ response for each of these glasses, immediately after preparation, is plotted against the hygroscopicity in figure 1 , and the change in $\mathrm{pH}$ response with time is shown in figure 2. Figure 1 shows that the glasses fall in their correct order of hygroscopicity similar to the data in table 2 and reemphasizes the finding that the $\mathrm{pH}$ response increases very rapidly with increase in the hygroscopic property of the glasses. The numerical values for the second set of electrodes do not agree exactly with those of the first group. In order to obtain exact reproducibility, successive electrodes of the same glass would have to be of equal thickness to maintain identical electrical resistance. This is especially pertinent for glasses of high electrical resistance. Further, in blowing the electrodes the composition of the outer surface of the glass is altered by volatilization of some of the consitutents of the glass by the blast lamp, and as the points for the less hygroscopic glasses lie on the steep portion of the curve, slight changes would cause correspondingly large changes in $\mathrm{pH}$ response. Furthermore, the electrodes prepared from these less hygroscopic glasses are sluggish, causing some uncertainty as to the correct reading.

TABLE 3.-Comparison of hygroscopicity and $\mathrm{pH}$ response at $25^{\circ} \mathrm{C}$ of some typical commercial and optical glasses after soaking the electrodes for various lengths of time in distilled water

\begin{tabular}{|c|c|c|c|c|c|c|c|c|c|c|c|c|}
\hline \multirow{2}{*}{ Glass } & \multirow{2}{*}{$\begin{array}{l}\text { Water } \\
\text { sorbed }\end{array}$} & \multicolumn{11}{|c|}{$\mathrm{pH}$ response, $\mathrm{mv}$ per $\mathrm{pH}$. Time of soaking, days- } \\
\hline & & 0 & 1 & 2 & 3 & 4 & 5 & 6 & 11 & 16 & 20 & 27 \\
\hline \multirow{3}{*}{$\begin{array}{l}\text { Corning } 015 \\
\text { Dish } \\
\text { Am. Ceram. Soe. No. } 1 . \\
\text { Goblet } \\
\text { BSC } 517\end{array}$} & \multirow{3}{*}{$\begin{array}{c}\mathrm{mg} / \mathrm{cm}^{3} \\
358 \\
88 \\
40 \\
20 \\
5.5\end{array}$} & $\begin{array}{l}59.0 \\
57.4\end{array}$ & \multirow{3}{*}{$\begin{array}{l}59.1 \\
58.7 \\
56.5 \\
53.0 \\
50.4\end{array}$} & $\begin{array}{l}59.1 \\
59.2\end{array}$ & 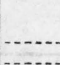 & 59.2 & \multicolumn{2}{|r|}{59.1} & 59.6 & 59.4 & 59.4 & 59.4 \\
\hline & & 56.0 & & 57.6 & 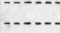 & 58.5 & 0 & 58.9 & 59.1 & 58.9 & 59.0 & 58.8 \\
\hline & & $\begin{array}{l}51.7 \\
48.3\end{array}$ & & 51.4 & 政 & . & 54.3 & 52.9 & $\begin{array}{l}54.7 \\
52.1\end{array}$ & 51.7 & 51.4 & $\begin{array}{l}54.1 \\
49.2\end{array}$ \\
\hline $\mathrm{BaC} 52_{2}$ & 2.2 & 33.7 & 49. 1 & & 52. 6 & 53. 2 & 53.1 & & 53.9 & 54.1 & 52.5 & 50.5 \\
\hline $\begin{array}{l}\text { Pyrex } \\
\text { Vycor } a\end{array}$ & $\begin{array}{l}1.8 \\
0.8\end{array}$ & 11.8 & 12.5 & 12.6 & 15.4 & 14.4 & N... & 12.9 & 14.2 & 14.0 & 13.9 & 14.5 \\
\hline & & & & & & & & & & & & \\
\hline
\end{tabular}

- Developed no definite $\mathrm{pH}$ response. 


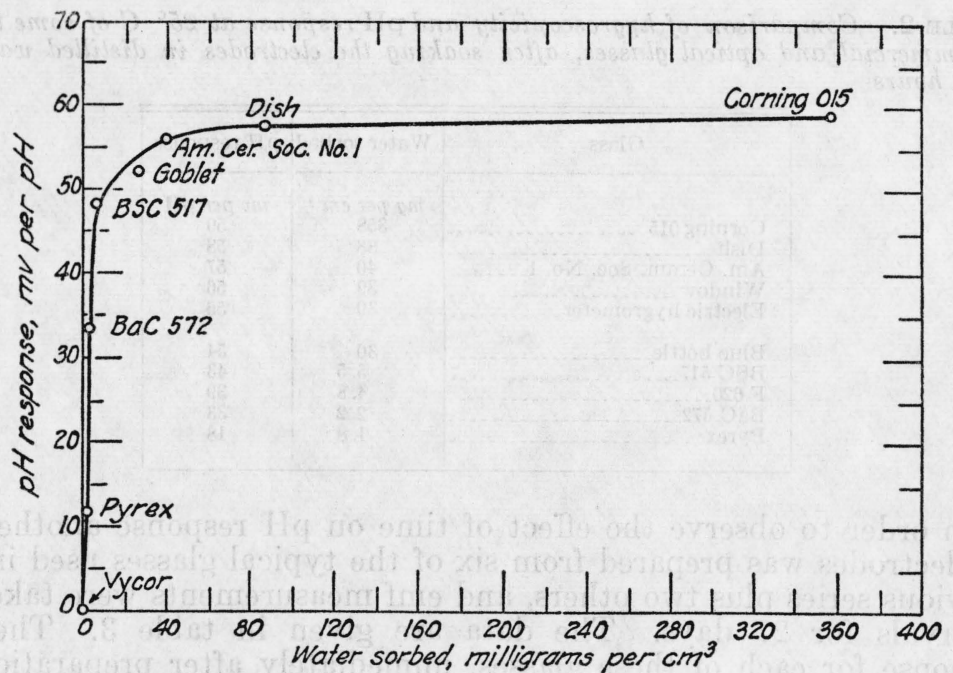

FIGURE 1.-Comparison of hygroscopicity and $\mathrm{pH}$ response of some typical commercial and optical glasses immediately after preparation of the electrodes.

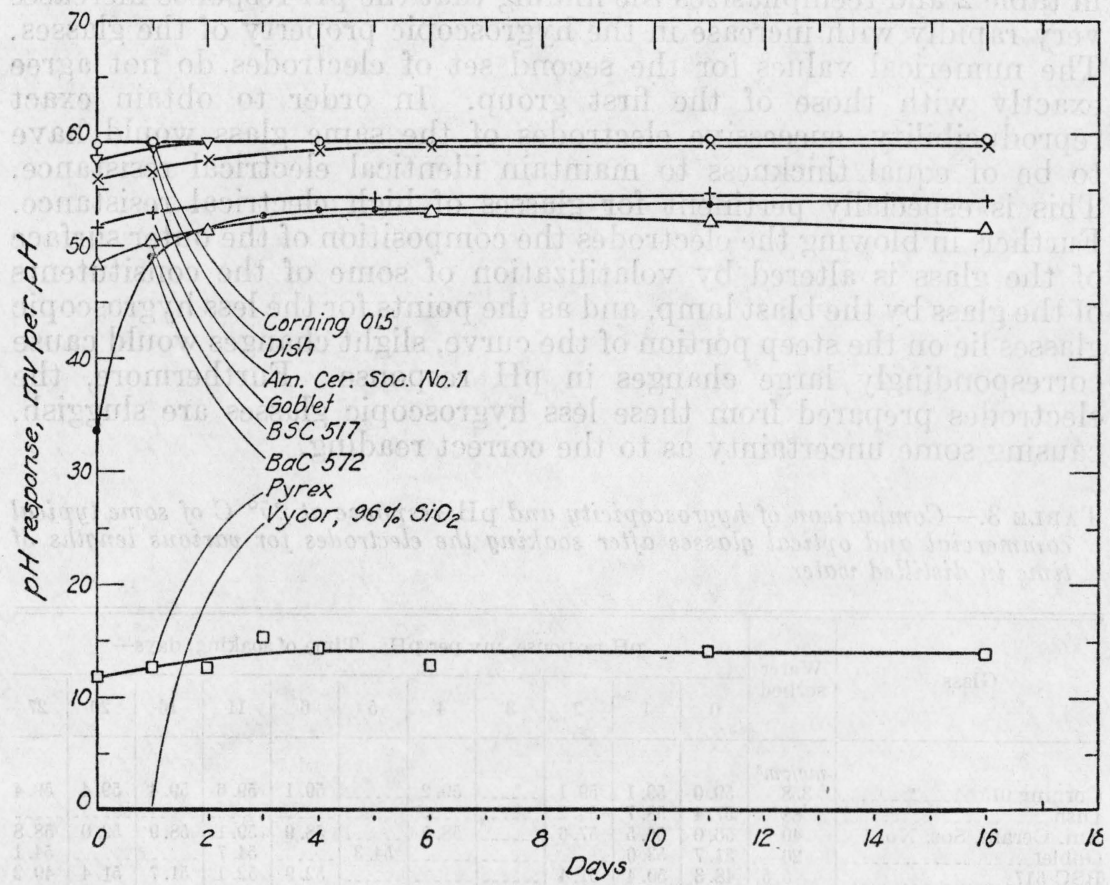

FIGURE 2.-Change in $\mathrm{pH}$ response with age of electrodes prepared from typical commercial and optical glasses. 
Figure 2 indicates that electrodes prepared from all the glasses improved in their $\mathrm{pH}$ response during immersion in distilled water. However, they did not continue improving indefinitely until the $\mathrm{pH}$ response attained the theoretical value of $59 \mathrm{mv}$ per $\mathrm{pH}$, but arrived near some definite upper limit for each electrode by the end of the fourth day. Although most of the glasses retained their relative positions, a glass such as the $\mathrm{BaC} 572$ did not do so. Undoubtedly this feature of $\mathrm{BaC} 572$ is caused by a differential behavior of this glass immersed in water or dilute acids in contrast to its reversible sorption of water vapor at high humidities. A preferential solution of certain constituents of the glass must have taken place during the soaking period because the effect is essentially irreversible, as shown by the finding that upon drying at $110^{\circ} \mathrm{C}$ the $\mathrm{pH}$ response did not return to the initial low value.

That a preferential solution of certain constituents of the BaC 572 glass does take place relatively rapidly, leaving a silica-rich surface $[7,4$, p. 151], is shown by the appearance of a nonreflecting film upon leaching polished surfaces in 1-percent $\mathrm{HNO}_{3}$ at room temperature. The BaC 572 glass develops a surface film of approximately onequarter wave length in about 24 hours, whereas periods of 2 weeks and more than 2 months are required for the BSC 517 and $\mathbf{F} 620$ glasses, respectively.

\section{2. pH RESPONSE OF GLASSES IN REGIONS OF CHANGING CHEMICAL DURABILITY}

Upon determining the hydrogen electrode function of these glasses at higher $\mathrm{pH}$ values, the relation of $\mathrm{pH}$ function to the hygroscopicity was not so rigorous. For example, when the $\mathrm{pH}$ response of these electrodes was tested with the three buffers normally used for calibrating glass electrodes, i. e., $\mathrm{pH}$ values of $4.01,6.77$, and $9.15,{ }^{5}$ the results were erratic. These values for $\Delta E / \Delta p H$ were considerably different from those obtained in the acid buffers. This was particularly true among the optical glasses. The choice of buffers with these $\mathrm{pH}$ values for examining the relation of $\mathrm{pH}$ response to hygroscopicity is obviously undesirable as the optical glasses are known to be severely attacked in this $\mathrm{pH}$ range $[4, \mathrm{p} .151]$, and voltage departures are known to accompany any change in chemical durability of the glass [5].

In order to emphasize the necessity for comparing the hygroscopicity with the electrode function obtained in a $\mathrm{pH}$ range over which the durability of the glass is constant, some voltage departures of the electrodes were ascertained over a $\mathrm{pH}$ range from 2 to 12 . These buffers were prepared from the Britton-Robinson Universal mixture [8] used in the previous determinations of durability [4, 5]. For experimental simplicity the Beckman glass electrode was taken as the reference electrode. This tacitly assumes that the Beckman glass responds perfectly to the hydrogen-ion activity of the buffer solutions, and that all voltage anomalies observed are to be accredited to the electrodes prepared from the experimental glasses. Such an assumption is known not to be rigorously true and is only legitimate for pur-

- These buffers were prepared and standardized by the pH Standards Section of the National Bureau of Standards. 
poses of illustration. If the reference electrode and the electrode prepared from an experimental glass had equal responses to hydrogenion activity, the voltage would remain constant over the entire $\mathrm{pH}$ range.

The results obtained by this procedure are listed in table 4 . A small voltage departure for the window and blue bottle glasses is evident in the vicinity of $\mathrm{pH} 6$, which becomes more pronounced beyond $\mathrm{pH} 9$. This is compatible with the durability curves previously observed for similar glasses in which detectable attacks were obtained by these same buffer solutions near $\mathrm{pH} 6$, with a more vigor-

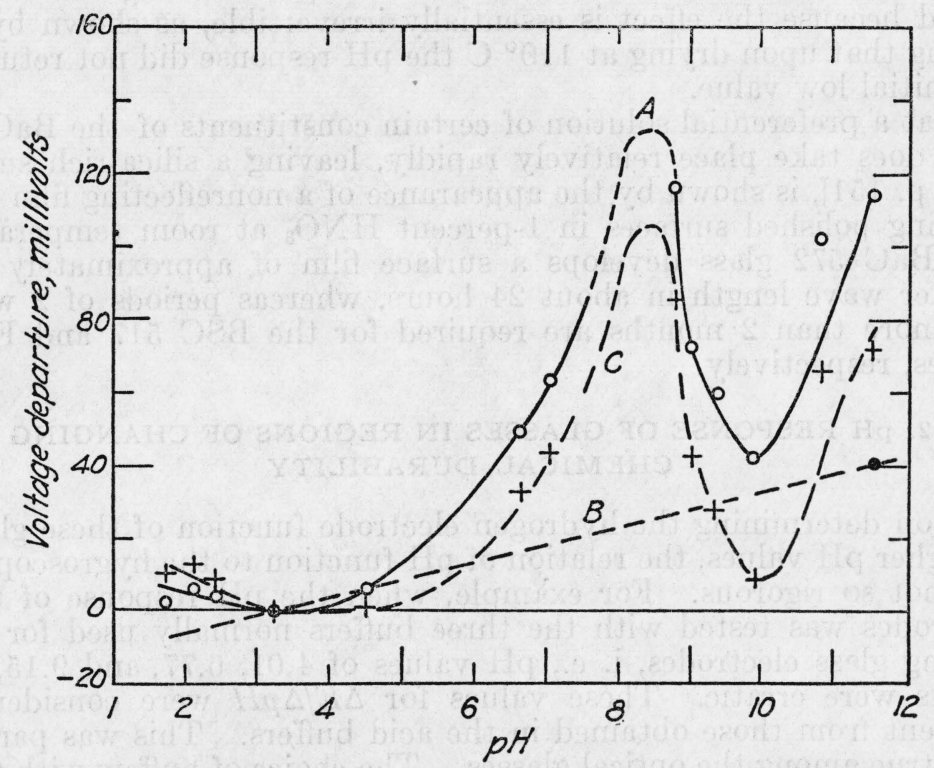

FIGURE 3.-Voltage departure of an electrode prepared from $\mathrm{BaC} 572$, using the Beckman glass electrode as the reference electrode.

Total voltage departure, $A$; voltage departure imposed by low hygroscopicity, $B$; voltage departure attributable to durability of the glass and other causes, $C$, using $\mathrm{pH} 3.3$ as the reference point.

ous attack beyond $\mathrm{pH} 9[4, \mathrm{p} .151]$. A conspicuous example of a voltage-departure curve that reflects this durability shift of the glass [4] is furnished by an electrode prepared from the $\mathrm{BaC} 572$ glass, figure 3 and table 5. Upon subtracting from the total voltage departure, the departure attributable to the low hygroscopicity, $59.0-54.1=4.9$ $\mathrm{mv}$ per $\mathrm{pH}$ (dashed straight line), one obtains a curve that presumably is the result of the durability shift of the glass and other causes, such as the electrode response to ions other than hydrogen [9].

The negative departures recorded in table 4 for the Corning 015 glass and the dish imply that their chemical durabilities are superior to the glass of the reference electrode in the region beyond $\mathrm{pH} 11$. 
T ABLE 4.-Voltage departures exhibited by electrodes prepared from various glasses, using the Beckman glass electrode as reference electrode

\begin{tabular}{|c|c|c|c|c|c|}
\hline \multirow{2}{*}{$\mathrm{pH}$} & \multirow{2}{*}{$\begin{array}{c}\text { Corning } \\
015\end{array}$} & \multicolumn{2}{|c|}{ Glass } & \multirow{2}{*}{$\begin{array}{c}\text { Blue } \\
\text { bottle }\end{array}$} & \multirow{2}{*}{ F 620} \\
\hline & & Dish & Window & & \\
\hline 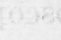 & $m v$ & $m v$ & $m v$ & $m v$ & $m v$ \\
\hline 1.9 & 0 & 0 & 0 & 0 & 0 \\
\hline 2.3 & 0 & 1 & 0 & 0 & 3 \\
\hline $\begin{array}{l}3.3 \\
4.3\end{array}$ & $\begin{array}{l}0 \\
0\end{array}$ & $\begin{array}{l}0 \\
0\end{array}$ & $\begin{array}{r}0 \\
-1\end{array}$ & $\begin{array}{l}0 \\
0\end{array}$ & $\begin{array}{l}12 \\
28\end{array}$ \\
\hline 5.1 & 1 & 0 & 0 & 0 & 39 \\
\hline 5.9 & 1 & -1 & 2 & 0 & 53 \\
\hline 6.4 & 2 & -1 & 4 & 1 & 77 \\
\hline 6. 9 & 2 & 0 & 6 & 3 & 90 \\
\hline 7. 3 & 2 & 3 & 7 & 4 & 106 \\
\hline 8.6 & 1 & 0 & 13 & 8 & \\
\hline 9.5 & 1 & -1 & 13 & 11 & 154 \\
\hline 10.4 & 0 & -1 & 21 & 22 & 195 \\
\hline 11. 2 & -1 & -11 & 31 & 37 & 229 \\
\hline 11.6 & -2 & -22 & 39 & 47 & 269 \\
\hline
\end{tabular}

TABLE 5.-Voltage departure exhibited by an electrode prepared from BaC 572 glass, using the Beckman glass electrode as reference electrode

\begin{tabular}{|c|c|c|c|}
\hline $\mathrm{pH}$ & $\begin{array}{c}\text { Total } \\
\text { voltage } \\
\text { departure }\end{array}$ & $\begin{array}{c}\text { Voltage } \\
\text { departure } \\
\text { imposed by } \\
\text { low hygro- } \\
\text { scopicity }\end{array}$ & $\begin{array}{c}\text { Voltage } \\
\text { departure } \\
\text { attributed to } \\
\text { attack and } \\
\text { other causes }\end{array}$ \\
\hline & $m v$ & $m v$ & $m v$ \\
1.8 & 2 & -7 & 9 \\
2.1 & 6 & -6 & 12 \\
2.5 & 4 & -4 & 8 \\
3.3 & 0 & 0 & 0 \\
4.6 & 6 & 6 & 0 \\
6.6 & 49 & 16 & 33 \\
7.0 & 63 & 18 & 45 \\
8.8 & 116 & 27 & 89 \\
9.0 & 72 & 28 & 44 \\
9.4 & 60 & 30 & 30 \\
9.9 & 42 & 32 & 10 \\
10.8 & 102 & 37 & 65 \\
11.5 & 114 & 40 & 74 \\
\hline
\end{tabular}

\section{CONCLUSIONS}

The present work indicates that the $\mathrm{pH}$ response of an optical glass can furnish useful information as an indicator of serviceability, i. e., its ability to maintain a clear polished surface upon exposure to the atmosphere. In fact, it seems reasonable to expect satisfactory serviceability from any glass with a $\mathrm{pH}$ response of less than $57 \mathrm{mv}$ per $\mathrm{pH}$ at $25^{\circ} \mathrm{C}$ in acid solution. Two of the glasses tested that failed to maintain clear surfaces, Corning 015 and the glass dish, had very high hygroscopicity values and gave $\mathrm{pH}$ responses close to the theoretical. Glasses of intermediate hygroscopicity exhibit only a slightly poorer response. On the other hand, the superior glasses, both optical and industrial, exhibit very poor electrode function and low hygroscopicity. This evidence furnishes strong support for, or 
is certainly compatible with, the theory that the glass electrode functions as a water electrode [10].

The voltage departures that accompany any change in chemical durability of the glass somewhat complicate the interpretation of the experimental results, but this can be largely avoided by confining the voltage observations between $\mathrm{pH} 2.0$ and $\mathrm{pH} 4$.

The relation between the $\mathrm{pH}$ response and hygroscopicity of a glass adds pertinent data toward the formulation of an acceptable theory of the glass electrode. The asymmetry potential and most or perhaps all of the conspicuous voltage departures of the glass electrode [1, 10, 11] are, at least, qualitatively rationalized $[4,5,10,12,13]$. There still remains the problem of ascertaining whether the voltage responses of some glasses under special conditions to ions other than hydrogen are true equilibrium responses or merely voltage departures resulting from changes in chemical durability of the glasses under the imposed conditions.

The hygroscopicity data might readily eliminate the condenser theory of the glass electrode [3] as it seems unlikely that the more hygroscopic the glass the better would be the condenser and hence the better the electrode function.

\section{REFERENCES}

[1] Malcolm Dole, Glass electrode (John Wiley \& Sons, Inc., New York, N. Y., 1941).

[2] Donald Hubbard, Hygroscopicity of optical glasses as an indicator of serviceability, J. Research NBS 36, (1946) RP1706.

[3] M. R. Thompson, A metal-connected glass electrode, BS J. Research 9, 833 (1932) RP511.

[4] Donald Hubbard and Edgar H. Hamilton, Studies of the chemical durability of glass by an interferometer method, J. Research NBS 27, 143 (1941) RP1409.

[5] Donald Hubbard, Edgar H. Hamilton, and Alfred N. Finn, Effect of the solubility of glass on the behavior of the glass electrode, J. Research NBS 22, 339 (1939) RP1187.

[6] Hisato Yoshimura, Effect of water on the potential of the glass electrode, Bul. Chem. Soc. Japan 12, 359 (1937).

[7] Frank L. Jones, Durability of optical glass, J. Am. Ceram. Soc. 24, 119-22 (1941).

[8] H. T. S. Britton, Hydrogen ions, 2d ed., table 57 (c), p. 225 (D. Van Nostrand Co., Inc., New York, N. Y., 1932).

[9] B. Lengyel and E. Blum, The behavior of the glass electrode in connection with its chemical composition, Trans. Faraday Soc. 30, 461 (1934).

[10] M. Dole, The theory of the glass electrode. II. The glass as a water electrode, J. Am. Chem. Soc. 54, 3095 (1932).

[11] D. A. MacInnes and D. Belcher, Further studies on the glass electrode, J. Am Chem. Soc. 53, 3315-3351 (1931).

[12] Edgar H. Hamilton and Donald Hubbard, Effect of the chemical durability of glass on the asymmetry potential and reversibility of the glass electrode, J. Research NBS 27, 27 (1941) RP1400.

[13] W. Bräuer, The cause of asymmetric potentials of the glass electrode, $\mathbf{Z}$. Electrochem. 47, 638-9 (1941).

Washington, April 8, 1946. 